\title{
Effect of Partial Replacement of Ordinary Portland Cement (OPC) with Ghanaian Rice Husk Ash (RHA) on the Compressive Strength of Concrete
}

\author{
Derrick Nii-Laryea Botchway', Russell Owusu Afrifa ${ }^{2}$, Charles Yeboah Henaku1 \\ ${ }^{1}$ Civil Engineering Department, Takoradi Technical University, Takoradi, Ghana \\ ${ }^{2}$ Civil Engineering Department, Kwame Nkrumah University of Science \& Technology, Kumasi, Ghana \\ Email: niiderrick@yahoo.com, russellafrifa@gmail.com, chenaku@yahoo.com
}

How to cite this paper: Botchway, D.N.-L., Afrifa, R.O. and Henaku, C.Y. (2020) Effect of Partial Replacement of Ordinary Portland Cement (OPC) with Ghanaian Rice Husk Ash (RHA) on the Compressive Strength of Concrete. Open Journal of Civil Engineering, 10, 353-363.

https://doi.org/10.4236/ojce.2020.104027

Received: September 16, 2020

Accepted: December 11, 2020

Published: December 14, 2020

Copyright $\odot 2020$ by author(s) and Scientific Research Publishing Inc. This work is licensed under the Creative Commons Attribution International License (CC BY 4.0).

http://creativecommons.org/licenses/by/4.0/

cc) (i) Open Access

\begin{abstract}
The cost of cement has made concrete production expensive such that the housing deficit in developing countries is on the rise despite all the efforts by governments and other stakeholders to produce affordable housing units for the populace. Ashes of agricultural products such as rice husk, known as mineral admixtures may have pozzolanic characteristics which would be more beneficial to the housing industry in terms of strength gain and economy than being pollutants to the environment. Rice Husk Ash (RHA), because of its finely divided form and very high silica content and amorphousness, proved to be useful for strength gain of Rice Husk Ash Concrete (RHAC). Rice husk ash was manufactured by uncontrolled burning, ground, sieved and replaced with cement at $0 \%, 5 \%, 10 \%, 15 \%, 20 \%$ and $25 \%$ in mass for the mixes C20, C25, C30 and C35 where their compressive strengths were verified at 3, 7, 14, 21, 28, 56, 90 and 180 days. The X-ray diffraction pattern list indicated amorphous as well as diffused peak of about 8000 counts of $\mathrm{SiO}_{2}$ representing crystalline structures identified as cristobalite. A physical examination of the RHA showed very fine appearance, grey color and specific gravity of 2.06. The chemical analysis also revealed the existence of oxide content to be $55.8 \%$ representing $0.78 \%$ of $\mathrm{Fe}_{2} \mathrm{O}_{3}, 54 \%$ of $\mathrm{SiO}_{2}$ and $1.06 \%$ of $\mathrm{Al}_{2} \mathrm{O}_{3}$ representing $20.23 \%$ lower than the minimum value of $70 \%$ required for pozzolans. Generally, the compressive strength values decreased as the RHA content in the mixes increased but when compared to the control concrete the optimum replacement percentage of Ordinary Portland Cement (OPC) with RHA at 5\% showed an increase above the control concrete for C20 mix. The increase in the RHA in the mixes resulted in the high demand for water in all the mixes.
\end{abstract}




\section{Keywords}

Rice Husk Ash, Agricultural Waste, Mineral Admixture, Pozzolanic Activity, Compressive Strength

\section{Introduction}

The use of concrete in infrastructural developments in the world especially in developing countries has taken a center stage as the most expensive building material to be resourced as can be seen in the cost of housing units in Ghana.

In spite of this, through the years, governments, private investors and other stakeholders in developing countries have made efforts to provide affordable housing facilities for citizens, but greater populations continue to live in deplorable conditions due to their inability to afford for housing, thereby resulting in their exposure to unhealthy environments and hazard-prone structures [1]. In line with the objectives of governments and their development partners to improve the standard of living of citizens through the provision of affordable housing facilities, the cost of production of ordinary Portland cement being one of the major factors of the cost of housing units needs to be reduced drastically to make housing affordability the accelerator of economic development to be envisaged.

Rice husk ash has been used in Europe, Asia and the Americas as a partial replacement of cement in concrete to reduce the quantity of cement in concrete as well as improving the compressive strength based on the target strength expected.

In the quest of researchers to improve the properties of concrete, other requirements have been negatively affected, hence being consistent in keeping all the properties of the concrete at the optimum happens to be the ultimate to successfully using this versatile material in developing Ghana.

Rice husk ash is known to be a mineral admixture or specifically pozzolanic material which contains siliceous or both siliceous and aluminous compounds and in the presence of moisture reacts with Calcium Hydroxide to form cementitious compounds. The use of rice husk ash was mentioned in the 1920s but research and development which led to its application can be traced back to the 1970s [2]. Since then, several studies have been undertaken where ultrafine RHA was used as partial replacement of cement in concrete, as viscous modifying agent in self-compacting concrete, in low-cost sandcrete block production, in determining of its pozzolanic activity [3] as well as environmental and economic benefits being derived from it.

Due to concrete's appreciable performance in strength requirements, ease of usage in construction and its durability in the normal environment, it cannot be disputed that its use has become popular in the construction industry resulting in the estimation that, one ton of cement contributes to about one ton of carbon dioxide into the atmosphere [4]. Therefore, approximately $7 \%$ of the world's 
carbon dioxide emission is accountable for the production of OPC [5] which may be directly linked with the uncomfortable environmental temperatures associated with the ozone layer depletion, leading to global warming.

Considering the rate of increasing populations which is accompanied by sporadic infrastructural developments, it cannot be over-emphasized that, in the near future, the raw materials (limestone, clinker and gypsum) for the manufacture of cement which are obtained from the earth's crust may be in short supply due to their extraction and usage. Therefore, it is extremely important to be in the production of other pozzolanic materials apart from the most common ones like fly ash, silica fume and GBFS which would be in great supply to curtail the rate of production of OPC.

The ability of RHA to react with the cement and their other constituents in the concrete may depend on the mean grain size. Generally, RHA particles below 45 $\mu \mathrm{m}$ are capable of actively taking part in pozzolanic reactions [6] as opined that, longer grinding times will result in smaller average particles size of RHA [7].

In a study where Nigerian rice husk was used as partial replacement of cement in concrete, compressive strength of $27.68 \mathrm{~N} / \mathrm{mm}^{2}$ was obtained at 28 days for $5 \%$ RHA replacement as compared to the compressive strength of $29.5 \mathrm{~N} / \mathrm{mm}^{2}$ for the control concrete at 28 days. There was a marginal difference of 0.68 $\mathrm{N} / \mathrm{mm}^{2}$ between the 7 days strength of $17.51 \mathrm{~N} / \mathrm{mm}^{2}$ for the control concrete as compared to the $16.88 \mathrm{~N} / \mathrm{mm}^{2}$ attained for the 5\% RHA concrete. Generally, there was a decrease in strength as the \%RHA increased whilst the compressive strength increased with the hydration time. All the same the 28 days compressive strength of the 5\% RHA replacement of cement was above the specified value of $25 \mathrm{~N} / \mathrm{mm}^{2}$ for C25 concrete [8].

In spite of all these investigations that have been undertaken on the use of RHA in concrete and have yielded results, its Silica content and application is yet to be envisaged in Ghana due to the ignorance of the silica content of the Ghanaian RHA since varying geological formations and method of chemical analysis may influence the chemical content of soils and may translate into the amount of Silica in the RHA [9]. This is evident that not much research has been done to investigate the use of the Ghanaian RHA as a supplementary material in concrete as well as other applications.

The purpose of this study is to investigate the effect of partial replacement of cement with Ghanaian RHA on the compressive strength of concrete. The specific objectives are to evaluate:

1) The physical properties of the Ghanaian RHA.

2) The chemical composition of the Ghanaian RHA.

3) The workability, compressive strength and density of Ghanaian RHA concrete.

\section{Methodology}

In this experimental investigation, percentile replacement $(0 \%, 5 \%, 10 \%, 15 \%$, 
$20 \%$ and $25 \%$ ) of cement with RHA by weight to compare with conventional concrete experimental results for concrete mixes C20, C25, C30 and C35. A total of 128 concrete cubes were cast and their compressive strengths of RHAC in comparison with Conventional Concrete (CC) assessed.

\subsection{Material Source and Preparation}

Rapid Hardening Portland cement produced by Ghana Cement with 28-day strength of $42.5 \mathrm{~N} / \mathrm{mm}^{2}$ was used. River sand and crushed granite were the aggregates used. The rice husk was obtained from Asawaasi a suburb of Kumasi also in the Ashanti Region of Ghana.

\subsection{Physical Properties of Aggregates \& Ghanaian RHA}

Sieve analysis was conducted on each of the aggregates including RHA according to ASTM C136 to obtain their particle size distribution where after, particles were allowed to pass through stack of sieves with known openings and shaken for about 10 minutes using a mechanical test sieve shaker. Upon removal of the sieves, weight of sample retained on each sieve was recorded and subtracting the respective mass of each sieve from weight of sieve and content. After calculating the $\%$ passing by subtracting the cumulative percent retained from $100 \%$, a semi-logarithmic curve was plotted with ordinate axis being \% passing and the sieve sizes as abscissa (logarithmic scale). Specific gravity test was performed in accordance with ASTM C127-07 (1993) in which specific gravity was obtained from Equation (1) below.

$$
S \cdot G=A /(A-C)
$$

where $A=$ weight of oven dry specimen in air and $C=$ weight of saturated specimen in water. The water absorption of the aggregates (granite and Sand) were tested using the saturated surface dry test method according to ASTM C125 and obtained from Equation (2) below.

$$
\% \text { Water Absorbed }=\frac{B-A}{A} * 100 \%
$$

where $A=$ weight of oven dry specimen in air and $B=$ weight of saturated surface dry specimen in air.

\subsection{Chemical Composition of the RHA}

The X-ray Fluorescence method was used in the chemical analysis of the RHA. The sample was heated prior to fusing where $0.5 \mathrm{~g}$ of the rice husk ash and $6.5 \mathrm{~g}$ of fluxing material was placed in a crucible and $400 \mu \mathrm{l}$ of liquid Lithium Bromide was added to the sample before fusing. Available Sodium Oxide, Potassium Oxide and alkali as well as loss on ignition were determined in accordance with ASTM Designation: C311.

\subsection{Mixing and Casting}

The UK'S Department of Environment's (DOE), (1998) mix design for conven- 
tional concrete was adopted for the investigation. Concrete grade strength of 20 $\mathrm{N} / \mathrm{mm}^{2}, 25 \mathrm{~N} / \mathrm{mm}^{2} 30 \mathrm{~N} / \mathrm{mm}^{2}$ and $35 \mathrm{~N} / \mathrm{mm}^{2}$ was designed for all mixes involving partial replacement of cement with RHA $0 \%, 5 \%, 10 \%, 15 \%, 20 \%$ and $25 \%$ with a w/c ratio of 0.45 for all the mixes. The determination of the material proportions for each mix was done by weight batching. The mixing of the aggregates was performed in a metal tub with a shovel where the cement aggregates were exhaustively mixed to achieve a homogeneous mixture and the slump test carried out. Prior to mixing, the moulds of $150 \mathrm{~mm} \times 150 \mathrm{~mm} \times 150 \mathrm{~mm}$ were lubricated after which the concrete was placed in the cast iron moulds in three layers. Each layer was compacted with about 25 blows of a tamping rod after which the surface was dressed with a hand trowel and the specimens allowed to set for 24 hours before demoulded and cured in water tanks by total submersion to curtail the heat of hydration of the concrete. On day of testing, upon removal of the cubes from the water tanks and allowing to attain dry surface state for about 3 hours, then specimens were weighed and crushed.

\subsection{Slump and Compressive Strength Tests}

The slump cone test was performed by BS EN 12350-2 to determine the workability of the concrete mix by pouring the concrete in the cone in three layers with each layer being compacted with 25 blows of a $16 \mathrm{~mm}$ tamping rod. Upon lifting upwards of the cone after compaction, the slump is obtained by measuring the difference between the highest points on the concrete to the bottom of masonry level on top of the cone.

After each curing period the concrete cubes were drained of excess water by sun drying and the density of the specimen was determined by dividing the mass of air-dried specimen by the volume.

With the help of a universal compression Testing machine of capacity 1000 $\mathrm{kN}$, the Compressive Strength was determined by dividing the crushing load of the specimen by the cross-sectional area as prescribed by the European Standard (B S EN 12390-3:2002).

\section{Results and Discussion}

\subsection{Physical Properties of Ghanaian RHA}

The rice husk obtained was produced by uncontrolled burning at a temperature not exceeding $400^{\circ} \mathrm{C}$, ground for an hour and sieved through the 75 micrometer sieve in order to remove any impurities and large size particles to obtain a very fine product, irregular shape and grey colour as shown in Table 1 . The rice husk before burning, after burning and after grinding and sieving are shown in Figures $1(\mathrm{a})-(\mathrm{c})$ respectively.

\subsection{Water Absorption}

The 24-hour water absorption for Granite aggregates and sand were reported as 


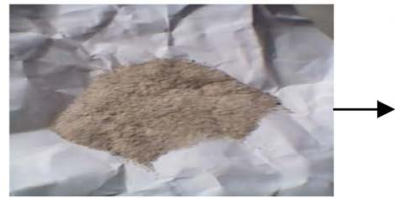

a

Rice husk

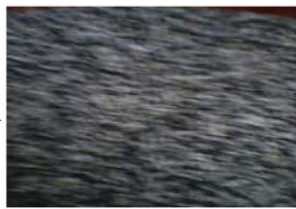

b

after burning

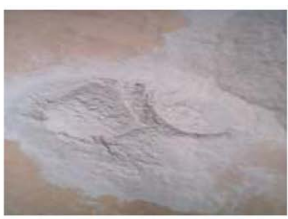

c

after grinding and sieving

Figure 1. Rice husk after burning, grinding and sieving.

Table 1. Physical properties of Ghanaian RHA.

\begin{tabular}{cc}
\hline PROPERTIES & PARTICULAR \\
\hline Colour & Grey \\
Shape & irregular \\
Particle size & $<45$ microns \\
Specific gravity & 2.06 \\
Appearance & Very fine \\
Fineness (Blaine) $\mathrm{m}^{2} / \mathrm{kg}$ & 351 \\
\hline
\end{tabular}

$0.66 \%$ and $2.7 \%$ respectively. The water absorption value determined for granite is within the maximum permissible limits except the sand as specified by the American Standard for Testing Materials, ASTM C128/C127 of 2\%.

\subsection{Specific Gravity of Sand, Granite and RHA}

The specific gravity for the fine aggregates, coarse aggregate and RHA were $2.608,2.6$ and 2.06 respectively.

The specific gravity of the RHA compared to 3.15 of OPC showed a difference of about $34.6 \%$. It was expected that the RHA and OPC would have nearly the same specific gravities despite the differences in raw materials and the methods of manufacturing of the RHA and the OPC. The method of manufacturing of the RHA may have accounted for the difference in specific gravities of the RHA and the OPC.

The specific gravity of the aggregates compared to minimum permissible standard specified by the ASTM C311-77 showed that the specific gravity of the aggregates was within the 2.4 and 2.9 as specified for normal weight aggregates.

\subsection{Chemical Analysis of Ghanaian RHA}

The total percentage composition of Iron Oxide $\left(\mathrm{Fe}_{2} \mathrm{O}_{3}=0.78 \%\right)$, Silicon dioxide $\left(\mathrm{SiO}_{2}=54 \%\right)$ and Aluminum Oxide $\left(\mathrm{Al}_{2} \mathrm{O}_{3}=1.06 \%\right)$ was found to be $55.84 \%$. This value is about $20.23 \%$ lower than the required value of $70 \%$ minimum for pozzolanas [10] and is $24.7 \%$ lower than $73.15 \%$ reported by [11]. The loss on ignition obtained was $18.25 \%$. This value is $34.2 \%$ more than $12 \%$ maximum as required for pozolanas. This means the RHA contains little unburnt carbon which may have reduced the pozzolanic activity of the ash. The loss on ignition obtained is $2.6 \%$ more than the value (17.78\%) reported by [11]. This indicates 
that the Ghanaian RHA produced a slight amount of un-burnt carbon compared to the Nigerian RHA. The reduced value of the $54 \%$ silica compared to the $70 \%$ minimum for pozzolans as well as the increased value of LOI may have resulted from the method of preparation of the ash and the species of the rice husk used respectively. The Magnesium Oxide content of $1.31 \%$ satisfies the required value of $4 \%$ maximum.

\subsection{X-Ray Diffraction Analysis}

The XRD analysis was performed at the University of Ghana, Physics Department to determine the Silica form of the RHA powder samples using an $\mathrm{x}$-ray diffracto-meter with $\mathrm{CuK} \alpha$ radiation at $45 \mathrm{kV} / 40 \mathrm{~mA}$ and scanning from $2 \theta=$ 10.02 - 59.98. The pattern list shown in Figure 2 has a hump, indicating amorphous as well as diffused peak of about 8000 counts at $\theta=23^{\circ}$ of $\mathrm{SiO}_{2}$ representing it as crystalline structures identified as crystoballite. This suggests that the RHA used, is in both amorphous and crystalline forms.

\subsection{Particle Size Distribution of RHA and Aggregates}

The particle size distribution for RHA, coarse and fine aggregates are presented in Figures 3-5 respectively.

The grading of all aggregates was referenced from BS 882 (1992) and it is clearly seen that the fine aggregates falls within the upper and lower limits as specified by the code provisions.

The Granite coarse aggregates however are seen to have fallen below the acceptable lower limit specified by BS 882 (1992). It can therefore be concluded that the gradation of coarse granite aggregate represents a narrow size range aggregate. The curve is near vertical and occupies only a small range of aggregate as specified in the small range with the creation of unfilled voids due to lack of different size particles to fill the void spaces. A conclusion can therefore be drawn that both aggregates (Figure $3 \&$ Figure 4 ) are likely to produce concrete with high void content and are indicative of open graded aggregates.

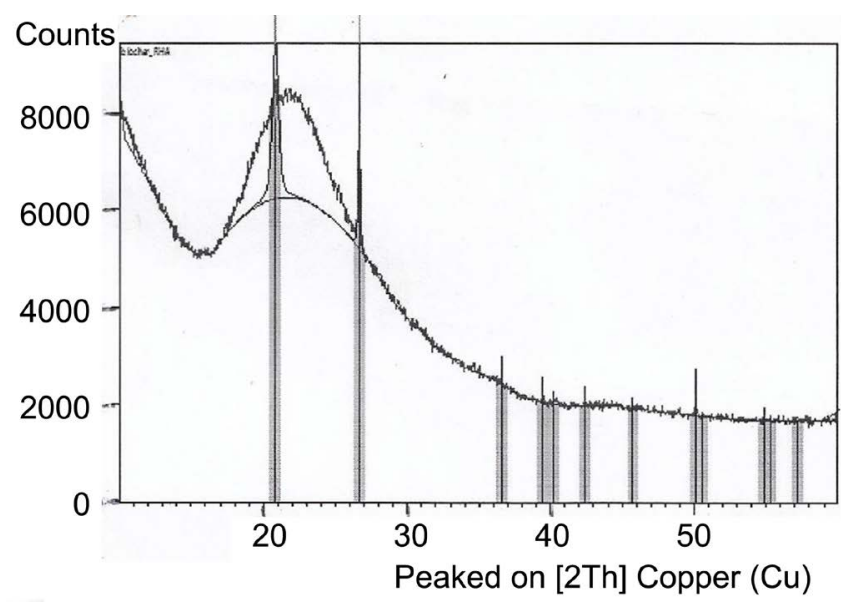

Figure 2. X-ray diffraction pattern of Ghanaian RHA. 


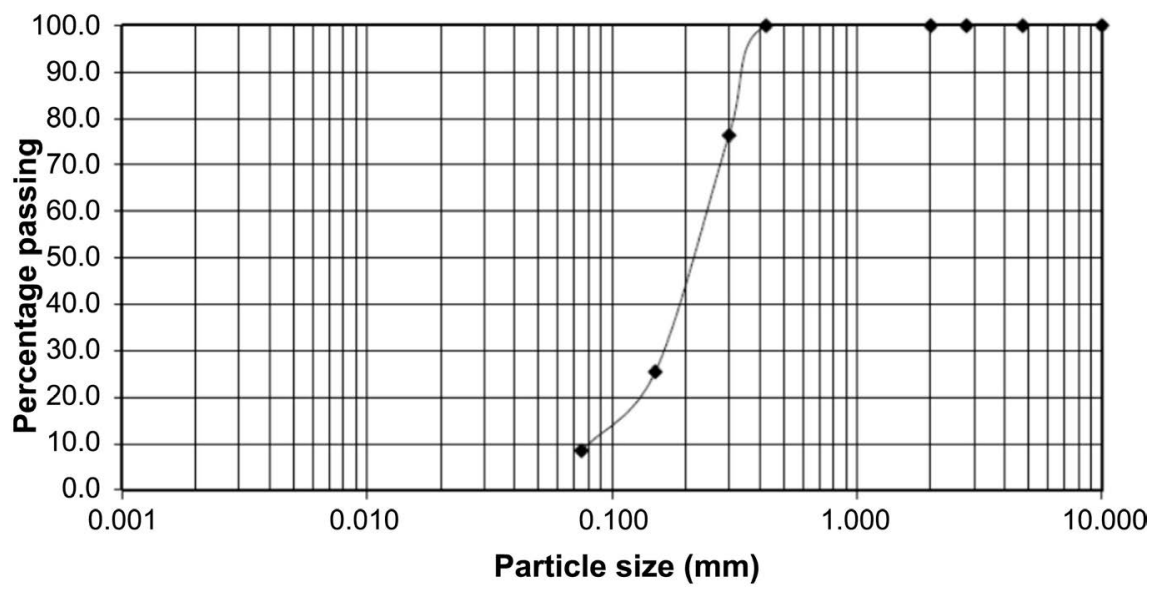

Figure 3. Particle size distribution for RHA.

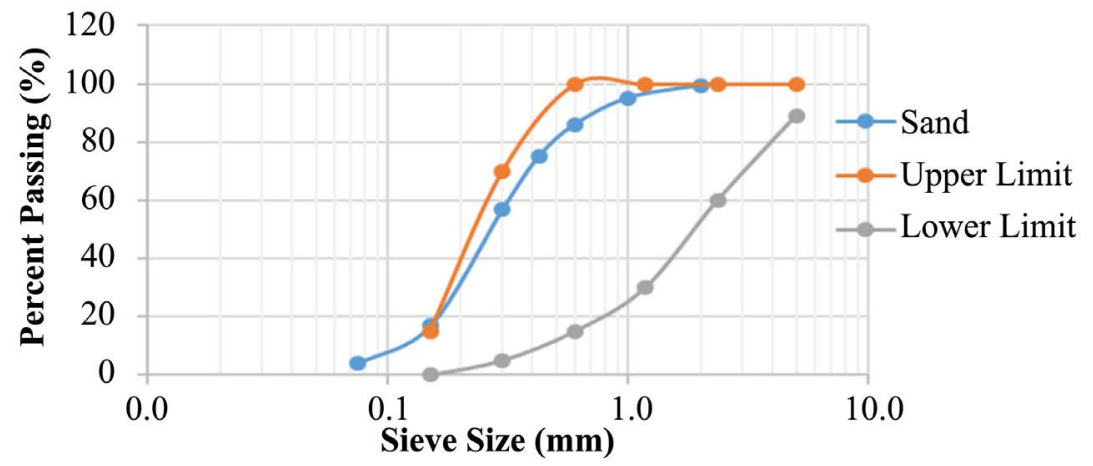

Figure 4. Particle size distribution for sand.

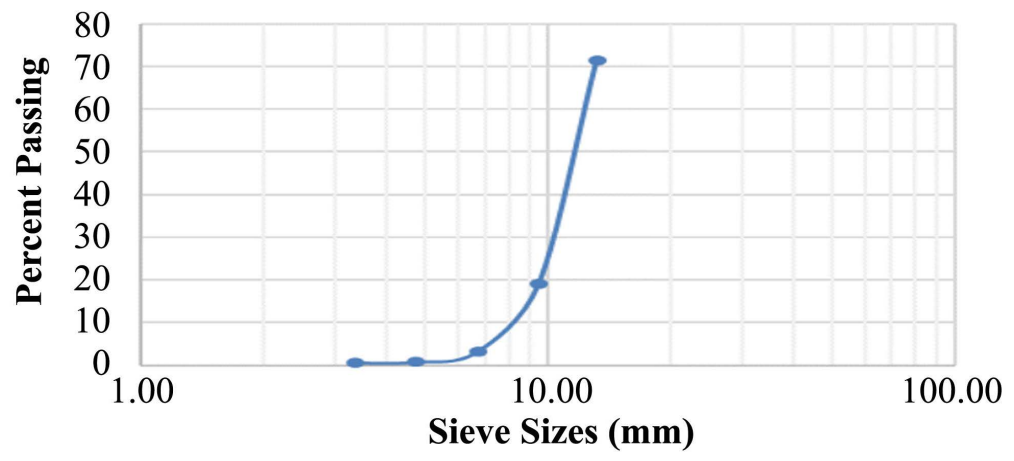

Figure 5. Particle size distribution for coarse aggregate.

\subsection{Compressive Strength of C20, C25, C30 and C35 RHA Concrete}

The values of compressive strength for the different mixes shows that generally, the compressive strength reduced as the RHA content increased. However, the compressive strength increased as the number of days of curing increased as shown in Figures 6-9.

The 28 day strength of the control concrete for C20 and C25 mixes were 21.8 $\mathrm{Nmm}^{-2}$ and $30.5 \mathrm{Nmm}^{-2}$ respectively and were above the specified value of 20 $\mathrm{Nmm}^{-2}$ and $25 \mathrm{Nmm}^{-2}$ except the C30 and C35 mixes whose compressive 
strengths were $28.1 \mathrm{Nmm}^{-2}$ and $32.8 \mathrm{Nmm}^{-2}$ respectively which were below the specified value of $30 \mathrm{Nmm}^{-2}$ and $35 \mathrm{Nmm}^{-2}$. Amongst all the percentage replacement of cement with RHA, the strength of the 5\% RHA concrete for C20 showed an increase in compressive strength from the control concrete compressive strength of $21.8 \mathrm{Nmm}^{-2}$ to $22.2 \mathrm{Nmm}^{-2}$ and decrease in the compressive strength from the control concrete compressive strength of $30.5 \mathrm{Nmm}^{-2}$ to 29.5 $\mathrm{Nmm}^{-2}$ for C25. The strength development process involved a chemical reaction in which the $\mathrm{Ca}(\mathrm{OH})_{2}$ in liquid phase from hydrated cement is fixed with the silica in the pozzolana. At the lowest percentage replacement level of 5\% RHA, the silica from the RHA was in required amounts such that the hydration process produced concrete cubes with high compressive strength.

For all the mixes, as the replacement levels of the RHA increased from $10 \%$, $15 \%, 20 \%$, and $25 \%$ the compressive strength decreased. This may be as a result of the amount of RHA in the mixes being higher than required to combine with the liberated Calcium hydroxide in the cement during the hydration process. During the process the excess silica is substituted by part of the hydrated silicates and aluminates and consequently causing a reduction in strength [12].

\section{GRAPH OF COMPRESSIVE STRENGTH AGAINST CURING AGES FOR C20 RHA CONCRETE}

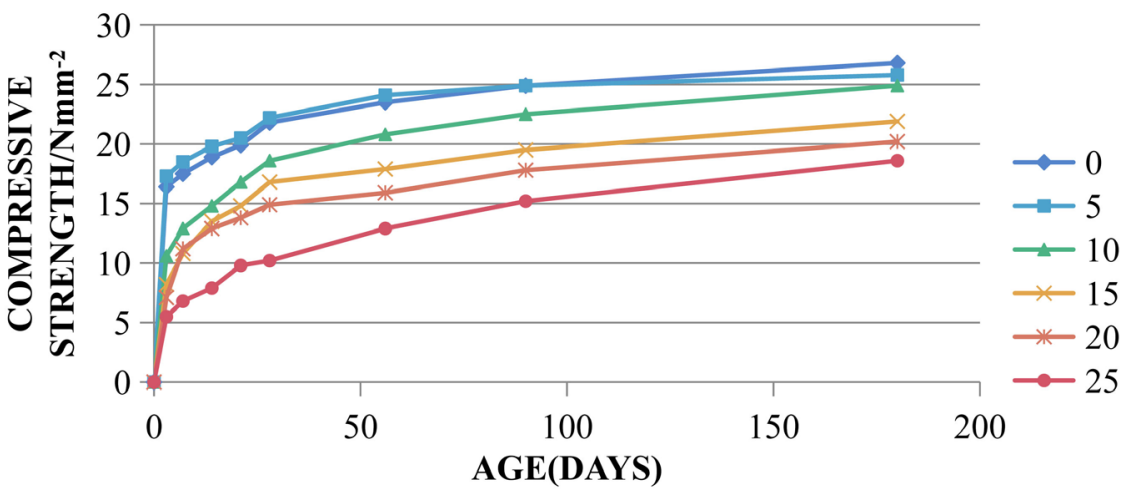

Figure 6. Variation of compressive strength against curing days.

\section{GRAPH OF COMPRESSIVE STRENGTH AGAINST CURING DAYS FOR C25 RHA CONCRETE}

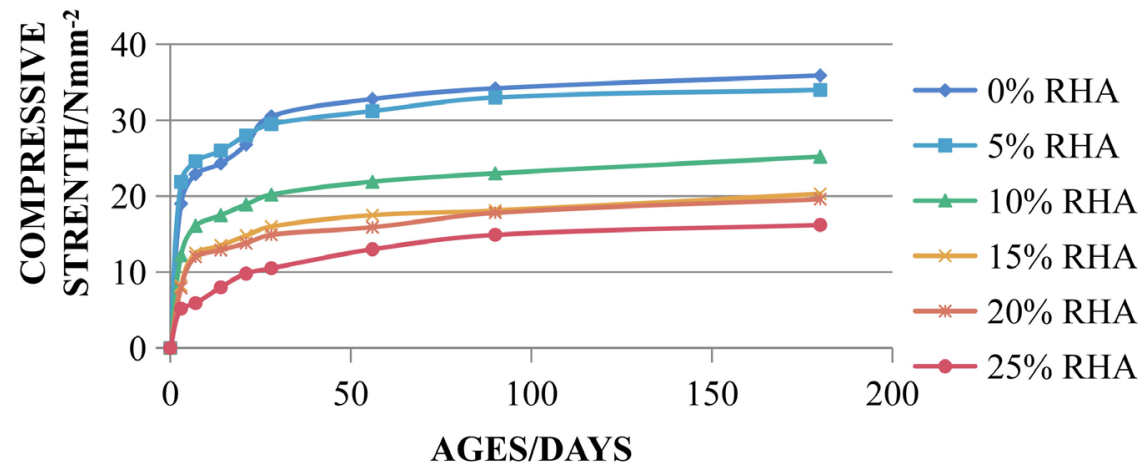

Figure 7. Variation of compressive strength against curing days for various RHA content. 


\section{GRAPH OF COMPRESSIVE STRENGTH AGAINST CURING DAYS FOR C30 CONCRETE}

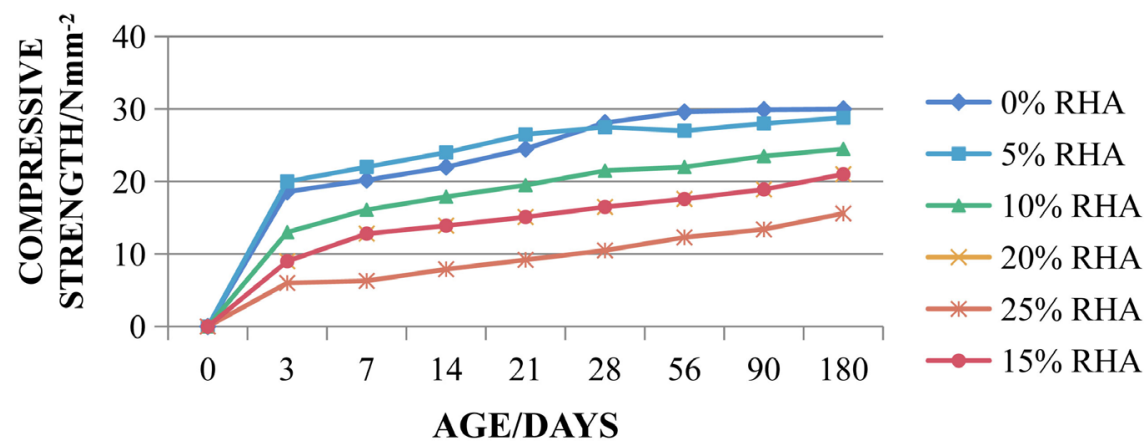

Figure 8. Variation of compressive strength with curing days for various RHA content.

\section{GRAPH OF COMPRESSIVE STRENGTH AGAINST CURING DAYS FOR C35 RHA CONCRETE}

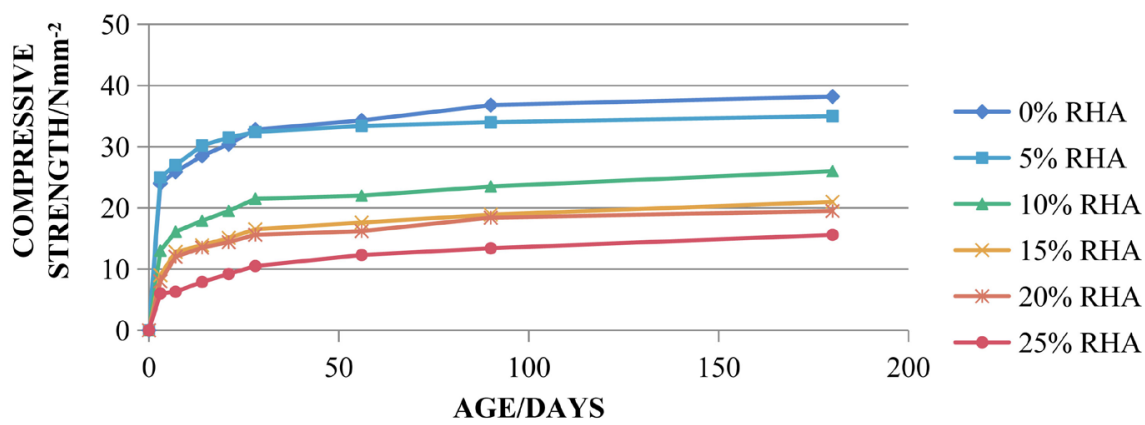

Figure 9. Variation of compressive strength against curing days for various RHA content.

\section{Conclusions}

The high scale use of agricultural wastes such as RHA will not only reduce cost to enable low-income earners to have the ability to afford housing and further curtail the pollution of the atmosphere by the manufacture of cement.

The results for the chemical analysis showed a low percentage of metals in the samples tested. The RHA was found to have a high percentage of lignin which is not biodegradable and as such may add to the durability property of concrete not decaying when embedded.

Addition of RHA to the mixes resulted in a slight increase in the compressive strength of the Ghanaian rice husk ash concrete but further increase in the RHA resulted in the reduction in the compressive strength with an increase in the demand for water which accounted for the low workability of the RHA concrete. The optimum replacement of OPC with RHA taken at 28 days strength for all the grades C20, C25, C30 and C35 was at 5\%.

\section{Conflicts of Interest}

The authors declare no conflicts of interest regarding the publication of this paper. 


\section{References}

[1] MOFEP (2012) 2012 Annual Report on Petroleum Funds. Accra, Ghana.

[2] Gram, H.E. (1983) Durability of Natural Fibres in Concrete. Sweden: Swedish Cement and Concrete Research Institute of Technology, 1, 1-255.

[3] Cordeiro, G.C., Filho, R.D.T. and de Moraes Rego Fairbairn, E. (2009) Use of Ultra Fine Rice Husk Ash with High Carbon Content as Pozzolan in High Performance Concrete. Materials and Structures, 42, 983-992. https://doi.org/10.1617/s11527-008-9437-z

[4] Bilodeau A. and Malhotra, V.M. (2000) High-Volume Fly Ash System: The Concrete Solution for Sustainable Development. ACI Structural Journal, 97, 41-48. https://doi.org/10.14359/804

[5] Malhotra, V.M., Lastra, R. and Zhang, M.H. (1996) Rice Husk Ash Paste and Concrete: Some Aspects of Hydration and the Microstructure of Interfacial Zone between the Aggregate and Paste. Journal of Cement and Concrete Research, 6, 963-977. https://doi.org/10.1016/0008-8846(96)00061-0

[6] Nehdi, M., Duquette, J. and El-Damatty, A. (2003) Performance of Rice Husk Ash Produced Using a New Technology as a Mineral Admixture in Concrete. Journal for Cement and Concrete Research, 33, 1203-1210. https://doi.org/10.1016/S0008-8846(03)00038-3

[7] Habeeb, G.A. and Fayyadh, M.M. (2009) Rice Husk Ash Concrete: The Effect of RHA Average Particle Size on Mechanical Properties and Drying Shrinkage. Australian Journal of Basic and Applied Sciences, 3, 1616-1622.

[8] Obilade, I.O. (2014) Use of Rice Husk Ash as Partial Replacement for Cement in Concrete. International Journal of Engineering and Applied Sciences, 5, 11-16.

[9] Ugheoke, I.B. and Othman, M. (2012) A Critical Assessment and New Research Directions of Rice Husk Silica Processing Methods and Properties. Maejo International Journal of Science and Technology, 6, 430-448.

[10] ASTM (1978) Significance of Tests and Properties of Concrete and Concrete making Materials. American Society for Testing and Materials, West Conshohocken.

[11] Oyetola, E.B. and Abdulllahi, M. (2004) The Use of Rice Husk Ash in Low-Cost Sandcrete Block Production. Leonardo Electronic Journal Practices Technology, 5, 58-70.

[12] Dabai, M.U., Muhammad, C., Bagudo, B.U. and Musa, A. (2009) Studies on the Effect of Rice Husk Ash as Cement Admixture. Nigerian Journal of Basic and Applied Science, 17, 252-256. https://doi.org/10.4314/njbas.v17i2.49917 